\title{
Meningkatkan Hasil Belajar Peserta Didik Kelas Xi IPA 9 SMA Budi Utomo Perak Jombang Materi Peluang Dengan Model Team Assisted \\ Individualization(TAI)
}

\author{
Lilik Rachmawati ${ }^{1}$, Aslih Maulana ${ }^{2}$ \\ SMA Budi Utomo, Perak Jombang ${ }^{1}$ \\ Progam Studi PPG, Universitas Muhammadiyah Gresik ${ }^{2}$ \\ Email: lilikrachmawati354@gmail.com
}

\begin{abstract}
Abstrak
Penelitian ini bertujuan untuk mengetahui: apakah penerapan Team Assisted Individualization (TAI) pada materi pokok peluang dapat meningkatkan keaktifan dan hasil belajar peserta didik kelas XI IPA 9 di SMA Budi Utomo Perak Jombang. Penelitian ini menggunakan Penelitian Tindakan Kelas (Classroom Action Research) pada peserta didik kelas XI IPA 9 semester ganjil di SMA Budi Utomo Perak Jombang tahun pelajaran 2018/2019, dengan jumlah 27 peserta didik. Metode pengumpulan data yang digunakan adalah dokumen, observasi, dan tes evaluasi. Sedangkan indikator keberhasilan dalam penelitian ini adalah meningkatnya hasil belajar yaitu nilai rata-rata 70 dengan ketuntasan klasikal 75\%, keaktifan70\%.

Penelitian tindakan kelas ini dirancang dalam 2 (dua) siklus, setiap siklus ada 4 (empat) tahap yaitu perencanaan (planning), tindakan (action), Pengamatan(observation), dan refleksi (reflection), dan masing-masing siklus dilaksanakan dengan dua kali pertemuan, satu pertemuan diantaranya untuk evaluasi siklus.

Berdasarkan hasil penelitian bahwa pada pra siklus keaktifan peserta didik pada siklus I 69,31\% dan pada siklus II meningkat menjadi 79,629\%. Hasil belajar peserta didik mengalami peningkatan yaitu nilai rata-rata 70,74 dengan ketuntasan belajar klasikal $66,67 \%$ pada siklus I, dan pada siklus II rata-rata nilai peserta didik meningkat menjadi 71,44 dengan ketuntasan belajar klasikal mencapai $77,78 \%$

Dari dua siklus tersebut jelas bahwa ada peningkatan keaktifan peserta didik maupun hasil belajar setelah diterapkannya model pembelajaran Team Assisted Individualization (TAI).

Dari data tersebut, dapat disimpulkan bahwa model pembelajaran Team Assisted Individualization (TAI) dengan melalui delapan langkah- langkahnya dapat meningkatkan keaktifan dan hasil belajar peserta didik pada pokok materi peluang kelas XI IPA 9 SMA Budi Utomo Perak Jombang Tahun 2018/2019. Keberhasilan penggunaan metode tersebut diharapkan bisa digunakan sebagai alternatif pendekatan pembelajaran yang inovatif. Selanjutnya para guru dapat lebih berkreasi dalam menggunakan model pembelajaran yang sesuai dengan tujuan pembelajaran.
\end{abstract}

Katakunci: Hasil belajar, Team Assisted Individualization(TAI)

\footnotetext{
Abstrack

This study aims to determine: whether the application of Team Assisted Individualization (TAI) on the subject matter of opportunities can improve the
} 
activeness and learning outcomes of students in class XI IPA 9 in SMA Budi Utomo Perak Jombang. This study uses a Classroom Action Research on 9th grade students of IPA 9 odd semester at High School Utomo Budi Perak Jombang in 2018/2019, with a total of 27 students. Data collection methods used are documents, observations, and evaluation tests. While the indicators of success in this study are increased learning outcomes, namely an average value of 70 with $75 \%$ classical completeness, $70 \%$ activity.

This class action research is designed in 2 (two) cycles, each cycle there are 4 (four) stages, namely planning, action, observation, and reflection, and each cycle is carried out with two meeting times, one of them is for cycle evaluation. Based on the results of the study that in the pre cycle of student activity in the first cycle $69.31 \%$ and in the second cycle increased to $79.662 \%$. Student learning outcomes have increased by an average value of 70.74 with a mastery of classical learning $66.67 \%$ in the first cycle, and in the second cycle the average value of students increased to 71.44 with a mastery of classical learning reaching $77.78 \%$

From these two cycles it is clear that there is an increase in student activity and learning outcomes after the implementation of the Team Assisted Individualization (TAI) learning model.

From these data, it can be concluded that the learning model of Team Assisted Individualization (TAI) through its eight steps can improve the activeness and learning outcomes of students on the subject of opportunities for XI IPA 9 High School Utomo Perak Jombang 2018/2019. The successful use of these methods is expected to be used as an alternative approach to innovative learning. Furthermore, teachers can be more creative in using learning models that are appropriate to the learning objectives.

Keywords: Learning Outcomes, Team Assisted Individualization (TAI)

\section{PENDAHULUAN}

Belajar merupakan suatu proses pendewasaan manusia dari tidak tahu menjadi tahu untuk meningkatkan intelektual atau kecerdasan untuk membentuk kepribadian yang mulia. Islam mewajibkan umatnya untuk menuntut ilmu dan Allah akan memuliakan derajat umat yang mempunyai ilmu pengetahuan, sebagaimana Firman Allah SWT dalam surat Al Mujadalah yang berbunyi :
Artinya: Wahai orang-orang yang beriman! Apabila dikatakan kepadamu, "Berilah kelapangan di dalam majlis-

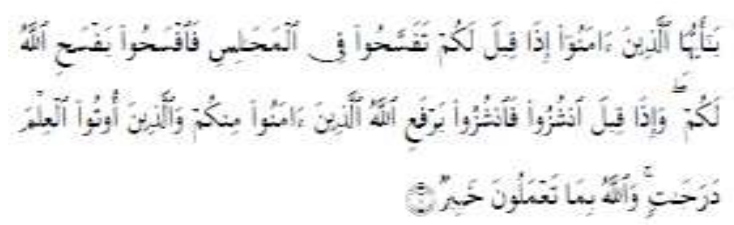

majlis, “ maka lapangkanlah, Niscaya Allah akan memberi kelapangan untukmu. Dan apabila dikatakan, “Berdirilah kamu,” maka berdirilah, niscaya Allah akan mengangkat (derajat) orang-orang yang beriman diantaramu dan orang-orang yang diberi ilmu pengetahuan beberapa 
derajat. Dan Allah Mahateliti apa yang kamu kerjakan”.(QS:58, 11)( Fadhil, 2006)

Salah satu ilmu yang dipelajari di sekolah adalah mata pelajaran matematika, mulai dari tingkatan rendah matematika sudah diperkenalkan dengan matematika. Dalam dunia pendidikan pelajaran matematika merupakan salah satu mata pelajaran pokok yang penting untuk diajarkan, bahkan matematika merupakan salah satumata ujidalam ujian nasional. Sebagian besar peserta didik masih menganggap matematika sebagai mata pelajaran yang menakutkan dan sangat dibenci hal tersebut dikarenakan matematika sebagian bersifat abstrak, dalam benak mereka matematika hanya menghafal berbagai rumus, sulit dan membosankan. Ini yang sering membuat para peserta didik antipati dengan matematika. Padahal dalam kehidupan sehari - hari kita semua tidak bisa lepas dari matematika. Baik untuk urusan dunia maupun urusan akhirat matematika sangat diperlukan.

Matematika juga mempunyai peran penting dalam perkembangan berbagai disiplin ilmu pengetahuan dan teknologi serta daya pikir manusia. Oleh karena itu pelajaran Matematika perlu diberikan kepada semua peserta didik mulai dari tingkat dasar untuk membekali mereka dengan kemampuan berpikir logis, sistematis, kritis dan kreatif serta mampu bekerja sama. Hal tersebut diperlukan agar peserta didik dapat memiliki kemampuan untuk memperoleh, mengelola dan memanfaatkan informasi untuk bertahan hidup pada keadaan yang selalu berubah, tidak pasti dan penuh persaingan. Untuk mewujudkan harapan tersebut pembelajaran matematika haruslah kreatif dan inovatif, maka diperlukan model model pembelajaran yang sesuai dengan materi pokok bahasan serta media pembelajaran yang sesuai, sehingga matematika yang bersifat abstrak bisa dikonkritkan dan mudah difahami.

Berdasarkan kenyataan yang ada di lapangan, model pembelajaran yang dilaksanakan di SMA Budi Utomo Perak Kabupaten Jombang cenderung monoton yaitu ceramah dan peserta didik diberi tugas. Dalam kegiatan belajar mengajar, para guru cenderung langsung menyampaikan materi dengan metode pembelajaran yang sama tanpa memperhatikan suasana kelas apakah sudah nyaman atau belum. Sedangkan pada peserta didik sendiri, mereka kebanyakan takut bertanya pada guru tentang materi pelajaran yang belum mereka pahami. Kedua kejadian tersebut akan menjadikan minimnya aktivitas peserta didik dan pemahaman materi yang 
telah disampaikan oleh guru atau pendidik.

Demikian juga pada pembahasan materi pokok peluang kelas XI di SMA Budi Utomo Perak Kabupaten Jombang masih banyak peserta didik yang kurang aktif dalam pembelajaran, belum terbiasa untuk mengungkapkan pendapat, bahkan masih ada peserta didik yang tidak tertarik pada pelajaran matematika. Keadaan ini mengakibatkan pada pelajaran matematika pokok materi peluang masih kurang maksimal, sehingga kemampuan peserta didik dalam memecahkan masalah yang berkaitan dengan materi juga masih lemah. Hal ini terjadi karena pada proses pembelajaran, metode yang digunakan pada pokok materi peluang kurang tepat, guru menggunakan metode ceramah dan diskusi klasikal.

\section{Team Assisted Individualization} (TAI) merupakan model pembelajaran kooperatif, dimana peserta didik ditempatkan dalam tim belajar kelompok beranggotakan 4-6 peserta didik secara heterogen baik jeniskelamin, kecakapan dan kinerja. Team Assisted Individualization TAI merupakan model pembelajaran yang mengarahkan peserta didik untuk dapat menyelesaikan permasalahan secara individual kemudian dilakukan saling memeriksa jawaban teman dalam kelompoknya, melalui diskusi dalam kelompok itu peserta didik memperoleh jawaban dari permasalahan peluang yang muncul. Hasil diskusi kelompoknya dipertanggung jawabkan bersama dalam presentasi.

Kegiatan belajar Team Assisted Individualization TAI ini (Ariani, 2017); (Halih, 2016) akan menimbulkan peserta didik aktif baik dalam kegiatan individu, aktif dalam diskusi kelompoknya, karena mereka tidak canggung apabila bertanya atau mempertahankan pendapatnya. Langkah berikutnya guru memberikan beberapa permasalahan peluang bentuk berbeda dikerjakan individu untuk memperkuat hasil kesimpulan yang telah diperoleh.

Berpijak pada latar belakang di atas, maka perlu diadakan penelitian "Peningkatan Hasil Belajar Matematika Pada Pokok materi peluang Dengan Model Pembelajaran Kooperatif Tipe Team Assisted Individualization (TAI) Pada Peserta Didik Kelas XI SMA Budi Utomo PerakKabupatenJombang Tahun Pelajaran 2018/2019”.

\section{METODE}

Penelitian yang digunakan penulis yaitu penelitian tindakan kelas (Classroom Action Research). Secara garis besar prosedur penelitian tindakan mencakup empat taraf : perencanaan (planning), tindakan (acting), pengamatan (observing), dan refleksi(reflekting). 


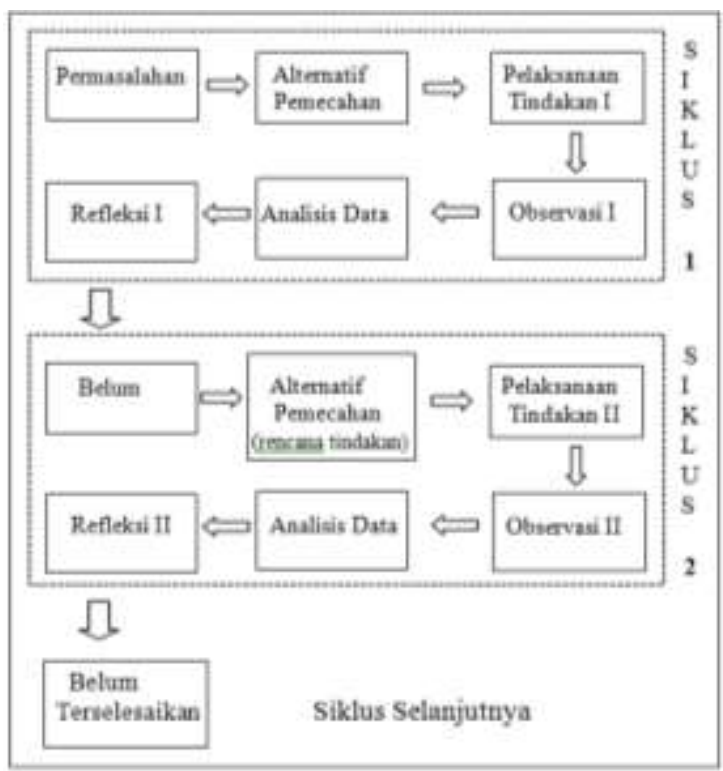

Dalam penelitian ini dilaksanakan dalam dua siklus, masing-masing siklus dengan tahapan perencanaan, pelaksanaan tindakan, observasi dan refleksi. Pelaksanaan penelitian dilakukan secara kolaborasi partisipasi antara guru pelajaran matematika SMA Budi Utomo Perak Kabupaten Jombang danpeneliti.

Teknik pengumpulan data dalam penelitian ini adalah sebagai berikut:

\section{Dokumenter}

Metode dokumenter digunakan untuk mendapatkan daftar nama peserta didik kelas XI IPA 9 SMA Budi Utomo Perak Kabupaten Jombang, serta untuk mendapatkan daftar nilai pada tahun pelajaran2017/2018.

Data keaktifan peserta didik selama berlangsungnya proses belajar mengajar pada saat dilaksanakan tindakan, diambil melalui lembar pengamatan.
2. Tes

Untuk mengukur keberhasilan peserta didik dalampembelajaran, baik pada siklus I maupun siklus II guru perlu mengadakan ulangan atau tes. Tes prestasi pada umumnya mengukur penguasaan dan kemampuan para peserta didik setelah mereka selama waktu tertentu menerima proses belajar- mengajar dari guru. Dengan metode tes ini dapat diketahui seberapa jauh penguasaan peserta didik pada materi yang telah mereka kaji.

Analisis yang digunakan secara umum terdiri dari proses analisis untuk menghitung prosentase keaktifan peserta didik dan mengetahui tingkat hasil belajar peserta didik.

1. Data keaktifan peserta didik

Analisa ini dilakukan pada instrumen lembar observasi dengan menggunakan teknik deskriptif presentase dengan perhitungan:

Prosentase $(\%)=\frac{n}{N} \times 100 \%$

Keterangan :

$\%=$ presentase keaktifan peserta didik $\mathrm{n}=$ skor yang dicapai $\mathrm{N}=$ skor maksimal Kriteria penilaian.

2. Data hasil belajar peserta didik.

Adapun rumus yang digunakan adalah :

a. Menghitung nilai rata-rata

Untuk menghitung nilai rata-rata menggunakan rumus 
$\bar{x}=\frac{\sum x}{N}$

Keterangan:

$\bar{x}=$ rata-rata nilai

$\sum x=$ jumlah seluruh nilai

$N=$ jumlah peserta didik

b. Menghitung ketuntasan belajar

Ketuntasan individu dihitung dengan menggunakan analisis deskriptif prosentase, yaitu :

prosentase $(\%)$

$=\frac{\text { jumlahskoryangdiperoleh }}{\text { jumlahskormaksimal }} \times 100 \%$

c. Ketuntasan Klasikal

Ketuntasan belajar klasikal dihitung dengan menggunakan analisis deskriptif prosentase, yaitu:

prosentase $(\%)$

$=\frac{\text { jumlahsiswayangtuntasbelajar }}{\text { jumlahseluruhsiswa }} \times 100 \%$

\section{HASIL DAN PEMBAHASAN}

Nilai keaktifan peserta didik dari pra siklus ke siklus 1dan dari siklus 1 ke siklus II aktivitas peserta didik dalam pembelajaran semakin baik dan mengalami peningkatan.

Pada pra siklus peserta didik banyak yang pasif, tidak bertanya, bermain sendiri, tidur, berbicara dengan teman sebelahnya dan tidak berani mengutarakan pendapat, akibatnya banyak peserta didik yang belum dapat menentukan jumlah titik sampel, titik sampel yang diharapkan muncul, baik menggunakan kombinasi ataupun menentukan peluang majemuk.

Pada siklus I peserta didik sudah mulai terlibat aktif dalam proses pembelajaran. Peserta didik banyak yang tidak bermain sendiri, berbicara dengan teman sebelahnya dan sudah banyak yang bertanya dan memahami bagaimana cara menentukan hal- hal yang berhubungan dengan cara menentukan nilai peluang suatu kejadian meskipun hasilnya belum optimal dan banyak peserta didik yang tuntas, serta beberapa peserta didik sudah berani mengerjakan soal di depan (papan tulis).

Pada siklus II peserta didik sudah semuanya terlibat aktif dalam proses pembelajaran. Hampir semua peserta relatif aktif, tidak tidur, tidak bermain sendiri dan berbicara dengan teman sebelahnya. Peserta didik secara individu hampir keseluruhan terlihat aktif bertanya dan menguasai konsep bagaimana cara menentukan nilai peluang suatu kejadian, serta sebagian besar peserta didik sudah berani mengerjakan soal di depan (papantulis).

Jadi secara keseluruhan dari pra siklus, siklus I dan siklus II, pelaksanaan proses pembelajaran materi pokok peluang menunjukkan adanya peningkatan 
keaktifan belajar, nilai rata- rata dan ketuntasan klasikal, sehingga pada siklus II semua indikator yang ditentukan sudah dipenuhi bahkan diatasnya, oleh karena itu penelitian cukup sampai di siklus II tidak perlu dilanjutkan ke siklus III

Untuk lebih jelasnya hasil keaktifan belajar, nilai rata- rata dan ketuntasan klasikal peserta didik pada pra siklus, siklus I dan siklus II dapat dilihat dalam tabel dan grafik berikut:

Tabel + 1. Perbandingan Hasil Pra Siklus, Siklus I dan Siklus II

\begin{tabular}{|l|c|c|c|c|}
\hline Instrumen & Pra sillus & Siklus I & Siklus II & Indikator \\
\hline Keaktifan belajar & & $68.67 \%$ & $79.48 \%$ & $75 \%$ \\
\hline Nilai rata-rata & 57.17 & 70.74 & 71.44 & 70 \\
\hline Ketuntasan Klasikal & $34.285 \%$ & $66.67 \%$ & $77.78 \%$ & $75 \%$ \\
\hline
\end{tabular}

Tabel 4.2. Perbandingan Hasil Pra Siklus. Siklus 1 dan Siklus II

\begin{tabular}{|l|c|c|c|c|}
\hline Instrumen & Pra sihlus & Sihlus I & Siklus II & Indikator \\
\hline $\begin{array}{l}\text { Jumlah Tuntas } \\
\begin{array}{l}\text { Jumlah Belum } \\
\text { Tuntas }\end{array}\end{array}$ & 12 & 18 & 21 & \\
$\begin{array}{l}\text { Jumlah Pescrta } \\
\text { Didik }\end{array}$ & 35 & 27 & 27 & \\
\hline $\begin{array}{l}\text { Ketuntasan Klasikal } \\
34,285 \%\end{array}$ & $666,67 \%$ & $77,78 \%$ & $75 \%$ \\
\hline
\end{tabular}

\section{PENUTUP}

\section{Simpulan}

1. Model pembelajaran tipe Team Assisted Individualization (TAI) dapat di laksanakan di kelas XI IPA 9 SMA BUDI UTOMO PERAK JOMBANG tahun pelajaran 2018/2019 pada bahasab peluang melalui depalan tahapan yaitu: (1) Team, (2) Placement Test, (3) Student Creative, (4) Team Study, (5) Team Scores and Team Recognition, (6) Teaching Group, (7) Facts Test, (8) Whole-ClassUnits.
2. Hasil belajar peserta didik kelas XI IPA 9 SMA BUDI UTOMO PERAK JOMBANG tahun pelajaran 2018/2019 dengan pembelajaran Team Assisted Individualization (TAI) pada proses kegiatan belajar mengajar pada pokok MATERI PELUANG mengalami peningkatan yaitu dari pra siklus dengan nilai rata-rata 57,17 , ketuntasan klasikal sebesar 34,285\%, meningkat menjadi 70,74 dengan ketuntasan klasikal menungkat menjadi66,67\%pada siklus I, dan pada siklus II rata-rata nilai peserta didik meningkat menjadi 71,44, dengan ketuntasan klasikal mencapai $77,78 \%$.

\section{Saran}

Sebagaimana hasil yang diperoleh dari penelitian, bahwamodel pembelajaran Team Assisted Individualization (TAI) dapat meningkatkan keaktifan dan hasil belajar peserta didik. Berdasarkan kenyataan yang diperoleh, maka saransaran yang dapat diberikan diantaranya adalah sebagai berikut:

1. Pembelajaran Team Assisted Individualization (TAI) dapat menjadi pertimbangan dalam pembelajaran untuk menjadikan motivasi, inovasi dan variasi pada proses pembelajaran. Model pembelajaran ini dapat meningkatkan keaktifan peserta didik serta cukup 
efektif untuk meningkatkan hasil belajar pesertadidik.

2. Hambatan - yang perlu diperhatikan dari pembelajaran Team Assisted Individualization (TAI) yang mungkin ditemui antara lain pengelolaan kelas yaitu penentuan anggota kelompok dan penataan meja kelompok memerlukan waktu relatif lama, lembar kerja peserta didik tercukupi untuk setiap anggota kelompok, komunikasi peserta didik ketika mengerjakan tugas merata untuk setiap kelompok. Untuk itu perencanaan baik waktu, administrasi, ataupun pengelolaan kelas harus di perhitungkan sebaik mungkin agar kendala - kendala tersebut dapat diminimalkan.

\section{DAFTAR PUSTAKA}

Ariani, T. (2017). Pembelajaran Kooperatif Tipe Team Assisted Individualization (TAI): Dampak Terhadap Hasil Belajar Fisika Siswa. Jurnal Ilmiah Pendidikan Fisika Al-BiRuNi, 6(2), 169-177.

Fadhil Abdur Rahman, H., Al-Qur'an Al- Karim dan Terjemah bahasa Indonesia, Menara Kudus, Kudus : 2006.

Halih, M. (2016). Pengaruh model pembelajaran TAI (team assisted individualization) terhadap hasil belajar siswa. Buana Matematika:
Jurnal Ilmiah Matematika Dan Pendidikan Matematika, 6(2), 4552. 